\title{
Sarcoma de Kaposi clásico en paciente fototipo VI. Primer reporte en Colombia
}

\author{
Luis Antonio Rodríguez Arrieta* \\ Denisse Maite Medina Tejeda* \\ Amilkar de Jesús Rodríguez Arrieta*** \\ Alcides Rodelo Martínez $z^{* * * *}$ \\ Francisco Camacho Chaljub ${ }^{* * * *}$
}

\begin{abstract}
* Residente de Medicina Interna Il año. Facultad de Medicina. Universidad de Cartagena. Cartagena. Bolívar. Colombia.
** Médico General. Facultad de Ciencias de la Salud, Universidad del Magdalena. Unidad de Cuidados Intensivos. Fundación Cardiotorácica Colombia. Barranquilla. Atlántico. Colombia.

*** Estudiante IX Semestre de Medicina. Grupo de Investigación Centro de Investigaciones Biomédicas-CIB. Facultad de Medicina. Universidad de Cartagena. Cartagena. Bolívar. Colombia.

**** Médico Dermatólogo. Docente Facultad de Medicina. Universidad de Cartagena. Cartagena. Bolívar. Colombia.

Correspondencia: Dr. Amilkar Rodríguez Arrieta. Dirección: B. Zaragocilla Av. Consulado \#49-106. Cartagena. Bolívar. Colombia. Correo electrónico: arodrigueza1@unicartagena.edu.co.Teléfono: 3008469216
\end{abstract}

\section{RESUMEN}

El sarcoma de Kaposi es un tumor vascular de bajo grado, que afecta piel y mucosas, pudiendo comprometer ganglios linfáticos y órganos internos. Generalmente está asociado a infección por virus herpes humano 8 , se clasifica en cuatro subtipos clínico-epidemiológicos, entre ellos el tipo clásico, que se manifiesta habitualmente en ancianos blancos, inmunocompetentes, de origen judío o mediterráneo. Se presenta el caso de un varón de 69 años, con fototipo VI, que desarrolló inicialmente máculas violáceas, eritematosas, de borde definido en región externa del pie izquierdo, que progresivamente se tornaron a placas y nódulos violáceos, acompañado de edema. Se realizó biopsia que mostró lesión vascular, cuya inmunohistoquímica presentó reactividad para CD30, CD34 y virus herpes humano 8 , confirmando un sarcoma de Kaposi en fase de nódulo. Este caso resulta excepcional y se debe tener presente en el diagnóstico diferencial; los reportes en Suramérica son escasos, siendo este el primero en Colombia. MÉD.UIS. 2017;30(3):129-33.

Palabras clave: Sarcoma de Kaposi. Herpesvirus Humano 8. Colombia.

\section{Classic Kaposi's sarcoma in phototype VI patient. First report in Colombia}

\begin{abstract}
Kaposi's sarcoma is a low-grade vascular tumor that affects the skin and mucous membranes and may compromise lymph nodes and internal organs. It is usually associated with human herpes virus infection 8 , classified into four clinical-epidemiological subtypes, including the classical type, which is usually manifested in elderly, immunocompetent white Jews or of Mediterranean origin. We present the case of a 69-year-old male, with phototype VI, who initially developed violaceous macules, erythematous, with defined border in the external region of the left foot, which progressively turned to violet plaques and nodules, accompanied by edema. A biopsy was performed showing vascular lesion, whose immunohistochemistry presented reactivity for $C D 30, C D 34$ and human herpesvirus 8 , confirming a Kaposi's sarcoma in the nodule phase. This case is exceptional and must be kept in mind in the differential diagnosis; the reports in South America are scarce, being the first in Colombia. MÉD.UIS. 2017;30(3):129-33.
\end{abstract}

Keywords: Sarcoma, Kaposi. Herpesvirus 8, Human. Colombia.

¿Cómo citar este artículo?: Rodríguez Arrieta LA, Medina Tejeda DM,Rodríguez Arrieta ADJ, Rodelo Martínez A, Camacho Chaljub F. Sarcoma de Kaposi clásico en paciente fototipo VI. Primer reporte en Colombia. MÉD.UIS. 2017;30(3):129-33.

Artículo recibido en Diciembre 31 de 2016 y aceptado para publicación en Mayo 12 de 2017 


\section{INTRODUCCIÓN}

El sarcoma de Kaposi (SK) es un tumor maligno vascular de bajo grado, localizado predominantemente en la piel y las mucosas, pudiendo afectar los ganglios linfáticos y los órganos internos. En 1994, Chang y colaboradores descubrieron la presencia de ADN de un nuevo tipo de virus herpes en muestras cutáneas de SK, a partir de ese momento se ha descrito la presencia del virus herpes humano 8 ( $\mathrm{VHH}-8)$ en todas las formas de Kaposi, virus que parece ser condición necesaria, pero no absoluta para el desarrollo de la enfermedad ${ }^{2}$. La seroprevalencia de infección por VHH-8 no es uniforme a través del mundo, hay cifras variables dependiendo del área geográfica, desde tasas bajas de $0-5 \%$ en el Norte de Europa, hasta tasas altas $>50 \%$ en países de África, así como tasas de seroprevalencia intermedia (5-20\%), como los países del Caribe ${ }^{1,3}$.

Se han descrito cuatro subtipos clínicoepidemiológicos del sarcoma de Kaposi, como son el clásico, el africano, el epidémico, y el iatrogénico. No obstante, su incidencia general ha disminuido con la introducción de la terapia antiretroviral de gran actividad contra el virus de la inmunodeficiencia humana $(\mathrm{VIH})^{1,3}$.

La variante clásica afecta predominantemente a ancianos de origen mediterráneo, se caracteriza por presentar un curso clínico lento, con aparición de lesiones en extremidades inferiores, las cuales progresan en sus dimensiones y elevación, se extienden centrípetamente hacia el tronco del cuerpo y por lo general no afectan mucosas ${ }^{3}$. El subtipo africano o endémico especialmente la forma linfadenopática, tiene un curso más agresivo que la variante clásica y se presenta mayormente en adultos negros de 30 a 45 años así como en niños provenientes de África ecuatorial, donde constituye el $9 \%$ de todos los tumores malignos ${ }^{1,4}$. El subtipo epidémico o asociado a $\mathrm{VIH}$, ocurre hasta 20 veces más en hombres homosexuales, y puede presentarse en personas que usan drogas intravenosas, ocurre principalmente entre los 20 a 50 años. Tiene predilección por la región cefálica (párpados, nariz y orejas), también pueden tener compromiso extracutáneo: gastrointestinal, pulmonar y ganglionar. Presenta un curso más agresivo que el resto de los subtipos, con sobrevida de semanas o meses ${ }^{1,4}$. El subtipo iatrogénico, puede ocurrir después de trasplante de órgano sólido o en pacientes que reciben tratamiento inmunosupresor, ocurre principalmente en individuos menores de 60 años, puede mejorar después de descontinuar la inmunosupresión, o presentarse con curso prolongado y agresivo si se asocia a trasplante ${ }^{1,4}$.

En América del Sur, se habían registrado no mucho más de 250 casos de sarcoma de Kaposi clásico (SKC) hasta el año 2005. En Colombia el registro histórico del Instituto Nacional de Cancerología, el de mayor extensión a nivel nacional, reportó entre 1935-1985 solo 79 pacientes con SKC, ninguno de ellos era de fototipo de piel $\mathrm{VI}^{3}$.

El tratamiento es guiado según la extensión de las lesiones y la manifestaciones clínicas del paciente para lo cual Enzinger 5 propuso una estadificación útil (Ver Tabla 1), si es local se puede manejar con radioterapia o quimioterapia local; si por el contrario, hay extensión importante hacia mucosas y órganos, se debe realizar manejo con quimioterapia sistémica. En la mayoría de los casos, tiene un curso crónico, indolente, y rara vez influye en la supervivencia, se han reportado cifras $2 \%$ de muerte por enfermedad generalizada en seguimiento a los 4,8 años, $24 \%$ murieron por malignidades secundarias y $22 \%$ murieron a causa de otras condiciones médicas ${ }^{6}$.

Tabla 1. Clasificación de Sarcoma de Kaposi según estadios de Enzinger.

\begin{tabular}{|c|l|}
\hline \multicolumn{2}{|c|}{ Estadios de Enzinger } \\
\hline E I & Cutáneo, localmente indolente. \\
\hline E II & Cutáneo, localmente agresivo. \\
\hline E III & $\begin{array}{l}\text { Generalizado, mucocutánea o con } \\
\text { compromiso ganglionar o ambos. }\end{array}$ \\
\hline E IV & Compromiso visceral. \\
\hline \multicolumn{2}{|c|}{ Subtipos } \\
\hline A & Sin manifestaciones sistémicas \\
\hline B & $\begin{array}{l}\text { Con manifestaciones sistémicas (pérdida } \\
\text { de peso mayor de 10\%, fiebre de más de 2 } \\
\text { semanas sin foco aparente). }\end{array}$ \\
\hline
\end{tabular}

Fuente: Modificado de: Brambilla L, Boneschi V, Taglioni M, Ferrucci S. Staging of classic Kaposi's sarcoma: a useful tool for therapeutic choices. Eur J Dermatol. 2003;13(1):83-6.

El objetivo de este artículo es reportar el primer caso en Colombia del SKC en un paciente de estirpe y localización caribeña donde existe nula incidencia de esta patología. Se documenta una enfermedad que, aunque es rara, deberá tenerse presente para el médico clínico dentro de las posibilidades diagnósticas. 


\section{Presentación del caso}

Varón con fototipo de piel VI, de 69 años, natural de Cartagena, Colombia, que presentó un tiempo de enfermedad de cuatro años, caracterizado por máculas en el borde externo del pie izquierdo, con progresión centrípeta, a nódulos violáceos, firmes, no dolorosos, algunos con superficie ulcerada, asociadas a edema moderado en la pierna derecha (Ver Figura 1).

Inicialmente, fue tratado como dermatomicosis durante 10 días sin respuesta a clotrimazol tópico, se realizó valoración por cirugía vascular, donde se descartó la posibilidad de estar frente un angiosarcoma. Posteriormente, el servicio de dermatología procedió a evaluar el caso, quienes decidieron realizar biopsia con inmunohistoquímica.

El paciente abandonó el seguimiento y reingresó dos años más tarde, con aumento en el número y tamaño de las lesiones, caracterizadas por múltiples nódulos violáceos indurados, no dolorosos, de tamaños variables y distribución simétrica en ambas piernas, los cuales no se extendían por encima de la región inguinal, acompañándose de ulceración en el tercio medio de la planta del pie derecho, con infección sobreagregada (Ver Figura 2).

En los exámenes auxiliares, el paciente presentó hemograma normal y el ELISA para Virus de Inmunodeficiencia Humana tipo 1 (VIH-1) fue negativo; test que se realizó dos veces para confirmar ausencia de falso negativo por período de ventana.

En la histopatología de la biopsia tomada hace 2 años, se evidenció una proliferación de vaso sanguíneos en la dermis superficial y profunda, con tendencia a la protruir en los espacios neoformados (Ver Figura 3), y marcó positivo en la inmunohistoquímica para CD30, CD34 y VHH-8 confirmando la presencia de SK en fase de nódulo. Se consideró un estadio III-A de la clasificación de Enzinger, por presentar una extensión mayor de 10 lesiones, sin compromiso visceral y sin manifestaciones sistémicas, con indicación de manejo sistémico con 6 ciclos de Doxorubicina liposomal $40 \mathrm{mg} / \mathrm{m}^{2}$ cada 2 semanas, y el paciente evolucionó de forma favorable, con remisión parcial del cuadro, sin presencia de edemas y disminución de más del 50\% del tamaño de las lesiones a los 6 meses de seguimiento.

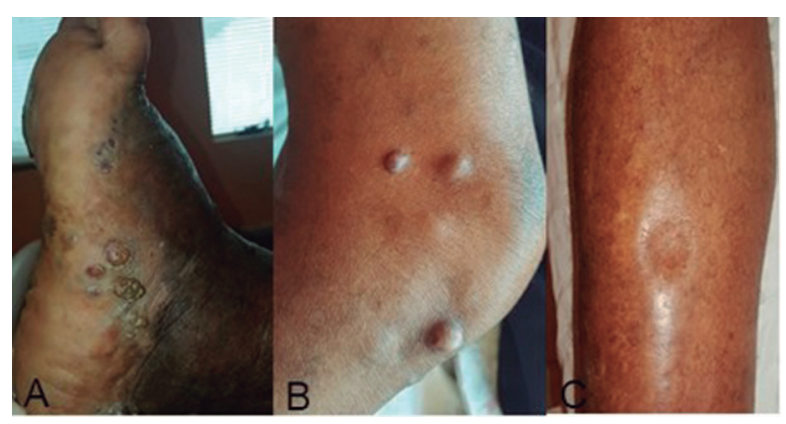

Figura 1. Lesión del paciente de 69 años de aparición inicial en la cara lateral del pie izquierdo. B. Lesiones nodulares a nivel de la rodilla. C. Edema con fóvea en pierna derecha del paciente. Fuente: Autores.

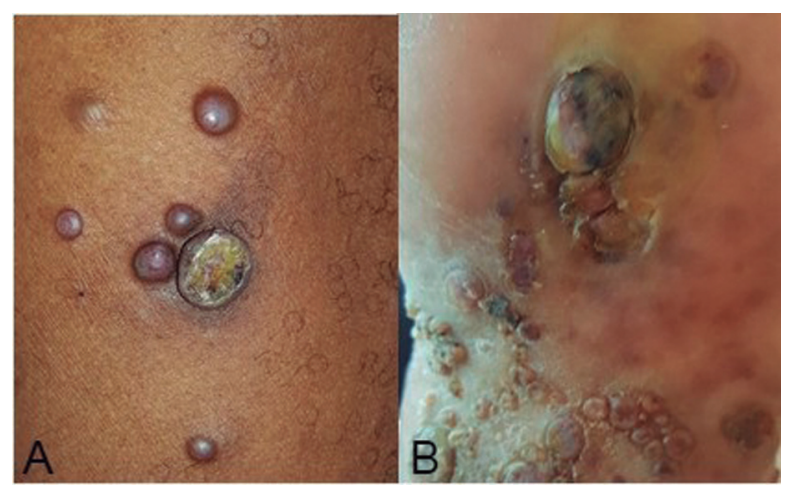

Figura 2. Nódulos violáceos, de múltiples tamaños, se observa lesión con superficie ulcerada. B. Nódulos con superficie inflamada, ulcerada y secreción purulenta.

Fuente: Autores.

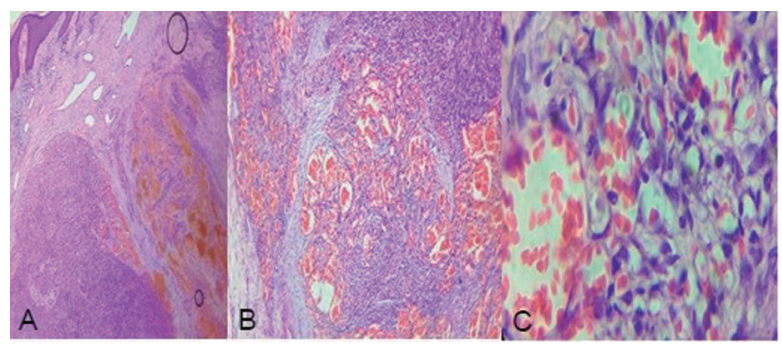

Figura 3. Proliferación nodular con vasos sanguíneos aberrantes, escaso infiltrado linfocitico y recubrimiento epidérmico. B. y C. Múltiples células fusiformes con distribución cohesiva, con presencia de neo-vasos y abundantes hematíes.

Fuente: Autores.

\section{Discusión}

El dermatólogo húngaro Moritz Kaposi en 1872, describió en 5 pacientes un "sarcoma idiopático, múltiple, pigmentado de la piel" con compromiso linfovascular, desde entonces esta patología tuvo 
poca trascendencia en el continente americano, pero a partir de la epidemia del SIDA y su asociación con el SK, el mundo científico tornó su atención sobre esta entidad ${ }^{1,2}$. Más aún, cuando en 1994, Chang et al. identificaron al herpesvirus asociado al SK o VHH-8, en una lesión de SK epidémico, cuyas células endoteliales presentaban alteraciones en genes, que traducían la expresión de factores estimulantes del crecimiento celular, potenciadas por la acción del virus y de la respuesta inflamatoria que este induce en las células inmunes, primordialmente a través de la Interleucina-6, generando células endoteliales elongadas y fusiformes ${ }^{1}$. Luego, en el 2010, el VHH8 fue declarado por la Agencia Internacional para Estudio del Cáncer, como agente carcinogénico del grupo I, es decir, que existe suficiente evidencia de ser carcinógeno en humanos ${ }^{7,8}$. Con esa asociación, la incidencia aumentó ostensiblemente, con posterior estabilización tras la instauración de una terapia antirretroviral efectiva?.

El SKC se presenta usualmente en paciente varones ancianos, inmunocompetentes, de la región mediterránea, descendientes de judíos Asquenazí'. La distribución mundial del SKC es muy variable con manifestaciones clínicas semejantes, no obstante, con ciertas discrepancias a los casos de SKC de Europa del Este, específicamente en Colombia se reportaron con un patrón de agresividad y compromiso linfático mayor ${ }^{9}$. García et al. reportaron un total de 79 casos de SKC, en un registro histórico de 1935 a 1985, del Instituto Nacional de Cancerología en Bogotá, cifra que correspondía al $1 \%$ de todas las neoplasias malignas, con una media de edad de 65 años, con una tasa hombre-mujer 8:1 y no se registró ningún paciente negro o descendiente de esta raza ${ }^{3,8}$. De los 250 casos reportados hasta 2005 con SKC en Suramérica, solo en 3 países (Brasil, Perú y Guyana Francesa) se identificó población americana de fototipo $\mathrm{VI}$, siendo de presentación excepcional como en el presente caso $^{10}$.

En Brasil, Montibeler et al"1. Reportaron 2 casos de SKC en hombres de piel oscura, en un estudio que comprendía 15 pacientes diagnosticados con SK entre los años 1986 y 2009, en un hospital de la ciudad de Vitória. Ambos pacientes tenían más de 65 años, las lesiones tuvieron un curso de evolución lento, caracterizadas por placas violáceas en pies, asociado a edema en piernas. El tratamiento recibido en uno de ellos fue con radioterapia, con buena respuesta y el otro paciente recibió talidomida 50-200 mg/día, presentando alivio del dolory del edema en miembros inferiores. Por otra parte, Carvalho et $\mathrm{al}^{12}$. Reportaron un caso de un hombre de 65 años, de piel negra, que presentó cuadro clínico de 8 años de evolución, consistente en edema en miembro inferior derecho, sin mejoría a tratamiento tópico, y en los últimos 5 meses empezó a desarrollar pápulas eritematosas violáceas en piernas y en flanco derecho, el miembro inferior derecho presentó linfedema y un nódulo linfoide de $4 \mathrm{~cm}$ de diámetro. Se realizó biopsia, que demostró presencia de células atípicas fusiformes, neoformación de vasos, eritrocitos extravasados, haciéndose diagnóstico de SK, la microscopía del nódulo linfático confirmó metástasis del sarcoma. Se realizó inicialmente quimioterapia con dos ciclos de bleomicina y adriamicina, sin reducción del tamaño de las lesiones. Luego se hizo tratamiento con radioterapia, con mejora significativa de las lesiones. Con respecto a los casos de Guyana Francesa y Perú, no fueron encontrados publicaciones que brindaran información de la presentación clínica, diagnóstico o tratamiento.

Si se realiza una comparación de los casos de Brasil, con el presente caso colombiano, se observa que todos se presentaron a edades mayores o iguales a 65 años, con curso insidioso, con patrón de lesiones similares en miembros inferiores, asociado a edema, aunque el caso colombiano se presentó con mayor compromiso ganglionar. El diagnóstico en todos los casos se hizo con biopsia e inmunohistoquímica y el tratamiento con mejores resultados fue la radioterapia, realizado en los casos de Brasil, resultado que fue favorable por tratarse de lesiones locales.

El diagnóstico de SKC suele ser sospechado en base a la aparición de las lesiones características (placas o nódulos de color púrpura, o pardo oscuro) y su distribución (sobre la piel, principalmente en extremidades inferiores). La biopsia se requiere para hacer un diagnóstico definitivo; a nivel histológico, la fase nodular evidencia abundantes células fusiformes y canales vasculares que contienen glóbulos rojos. La inmunohistoquímica es positiva para marcadores vasculares (CD31 o CD34) y/o marcadores linfáticos (D2-40), también detecta la presencia de antígeno nuclear asociado a latencia VHH-8 (LANA1) dentro de las células del huso 3 . Además, se puede realizar una reacción en cadena de la polimerasa de las lesiones cutáneas, para detectar secuencias amplificadas de ADN de $\mathrm{VHH}-8^{1,2,13}$.

El tratamiento local de las lesiones dérmicas con radiación, escisión quirúrgica, electro-cauterización y 


\section{SEPTIEMBRE - DICIEMBRE}

curetaje son generalmente efectivas. En casos más avanzados con compromiso dérmico generalizado o visceral, la radioterapia y quimioterapia han logrado relativamente un buen control de las lesiones y paliación efectiva a corto término. Los agentes citotóxicos más activos incluyen a los alcaloides de la vinca (vinblastina y vincristina), bleomicina, etoposido, antraciclinas liposomales y no-liposomales (doxorubicina y daunorubicina) y el paclitaxel, recientes estrategias terapéuticas se encuentran en fases de investigación y se cuenta con evidencia escasa como el interferón alfa recombinante, talidomida, sirolimus y el indinavirir, ${ }^{1,2,14,15}$.

\section{ConClusión}

Pocos casos previos de SKC en americanos con fototipo VI han sido descritos, se presenta este caso debido a sus características excepcionales. No hay evidencia de reportes previos en Colombia, así como en gran cuantía de otros países, lo cual es significativo y sirve de referencia para el clínico al momento de realizar el abordaje y ampliar el abanico de diagnósticos diferenciales de un paciente con dermatosis.

\section{Referencias Biblográficas}

1. Radu O, Pantanowitz L. Kaposi Sarcoma. Arch Pathol Lab Med. 2013;137(2):289-94.

2. Dittmer DP, Blossom D. Kaposi sarcoma associated herpesvirus pathogenesis (KSHV) - an update. Curr Opin Virol. 2013;3:238-44.

3. García A, Olivella F, Valderrama S, Rodríguez G. Kaposi's sarcoma in Colombia. Cancer Cytopathol. 1989;64(11):2393-8.

4. Rojo A. Sarcoma de Kaposi: revisión de la literatura e ilustración de un caso. Acta Médica Grupo Ángeles. 2013;11(1):23-31. Disponible en: http://www.medigraphic.com/actamedica

5. Enzinger FM, Weiss SW. Malignant vascular tumors. En: Enzinger FM, Weiss SW, eds. Soft Tissue Tumors $3 .^{a}$ ed. St. Louis: C.V. Mosby Co, 1995:641-77.

6. Hiatt KM, Nelson AM, Lichy JH, Fanburg-Smith JC. Classic Kaposi Sarcoma in the United States over the last two decades: a clinicopathologic and molecular study of 438 non-HIV-related Kaposi Sarcoma patients with comparison to HIV-related Kaposi Sarcoma. Mod Pathol. 2008;21(5):572-82.

7. Cioffi A, Reichert S, Antonescu CR, Maki RG. Angiosarcomas and other sarcomas of endothelial origin. Hematol Oncol Clin N Am. 2013;27(5):975-88.

8. Rohner E, Wyss N, Trelle S, Mbulaiteye SM, Egger M, Novak U, et al. HHV-8 seroprevalence: A global view. Syst Rev. 2014;(12):3-11.

9. Taddeo A, Presicce P, Brambilla L, Bellinvia M, Villa ML, Della Bella S. Circulating endothelial progenitor cells are increased in patients with classic Kaposi's sarcoma. J Invest Dermatol. 2008; 128(8):2125-8

10. Mohanna S, Maco V, Bravo F, Gotuzzo E. Epidemiology and clinical characteristics of classic Kaposi's sarcoma, seroprevalence, and variants of human herpesvirus 8 in South America: A critical review of an old disease. Int J Infect Dis. 2005;9(5):239-50.

11. Montibeler R, Oliveira AL, Martins L, Almeida E. Kaposi's Sarcoma: clinical and pathological aspects in patients seen at the Hospital Universitário Cassiano Antônio Moraes - Vitória Espírito Santo - Brazil. An Bras Dermatol. 2012;87(2):220-7.

12. Carvalho IM, Garção F, Abrahão L, Salaro CP, Carvalho RM. Classic Kaposi's sarcoma: a case report. An Bras Dermatol. 2001;76(2):195-9.

13. Brambilla L, Boneschi V, Taglioni M, Ferrucci S. Staging of classic Kaposi's sarcoma: a useful tool for therapeutic choices. Eur J Dermatol. 2003;13(1):83-6.

14. Jiménez K, Martínez JD, Hernández G, Garzón MA, Hormaza N, Lizarazo JI. et al. Tres variedades de sarcoma de Kaposi con compromiso gastrointestinal. Rev Col Gastroenterol. 2015;30(3):342-6.

15. Régnier-Rosencher E, Guillot B, Dupin N. Treatments for classic Kaposi sarcoma: a systematic review of the literature. J Am Acad Dermatol. 2013;68(2):313-31. 